\title{
PERSPECTIVA PEDAGÓGICA Y FILOSÓFICA DE UNICLARETIANA DESDE EL CONCEPTO DE JUSTICIA EDUCATIVA
}

\section{PEDAGOGICAL AND PHILOSOPHICAL PERSPECTIVE OF UNICLARETIANA FROM THE CONCEPT OF EDUCATIONAL JUSTICE}

\author{
AURA SMID DURÁN TÉLLEZ* \\ Recibido: 20 de agosto de 2017 - Aceptado: 20 de septiembre de 2017 - Publicado 31 julio de 2018 \\ DOI: 10.24142/raju.v13n26a11
}

\section{Resumen}

El contexto actual de las desigualdades sociales en Latinoamérica cuestiona y, al mismo tiempo, desafía el escenario de la educación superior en la búsqueda de procesos de transformación social. Estos desafíos se comprenden, en el marco de esta ponencia, desde la justicia educativa, entendida como la posibilidad de acceso con calidad a la enseñanza-aprendizaje como consecuencia de prácticas individuales y acciones colectivas. A partir de este panorama, y desde una reflexión teórica, se intentan identificar los aportes que ofrece la perspectiva pedagógica y filosófica de la Fundación Universita-

Trabajadora Social de la Fundación Universitaria Claretiana (Uniclaretiana), estudiante de la Especialización en Políticas Públicas para la Igualdad en América Latina, CLACSO, Argentina. Docente de la Uniclaretiana, Medellín. Correo electrónico: aura.duran.tellez@gmail.com 
ria Claretiana (Uniclaretiana) en su apuesta de educación superior de frontera, con mirada humanista, liberadora, crítica y contextual, como respuesta a las aspiraciones que tienen aquellas comunidades que afrontan realidades de pobreza, exclusión y violencia sociopolítica, especialmente indígenas, afrodescendientes y campesinas, de acceder a una universidad que se ajuste a su contexto y dinámicas de vida; no obstante, las exigencias del modelo socioeconómico y del sistema educativo en particular dificultan su materialización.

Palabras claves: justicia educativa, modelo educacional, enseñanza superior, educación de frontera.

\section{Abstract}

The current context of social inequalities in Latin America questions and, at the same time, challenges the higher education scenario in the search for processes of social transformation. These challenges are understood, within the framework of this presentation, from educational justice, understood as the possibility of quality access to teaching and learning as a result of individual practices and collective actions. From this perspective, and from a theoretical reflection, we try to identify the contributions offered by the pedagogical and philosophical perspective of the Claretian University Foundation (Uniclaretiana) in its commitment to higher education and inclusive, with a humanist, liberating, critical and contextual perspective, as a response to the aspirations of those communities that face the realities of poverty, exclusion and socio-political violence, especially indigenous people, African-descendents and peasants, to access a university that fits their context and life dynamics; nevertheless, the demands of the socioeconomic model and the education system in particular make it difficult to materialize.

Keywords: educational justice, educational model, higher education, inclusive education. 


\section{INTRODUCCIÓN}

La historia de los pueblos latinoamericanos no es diferente a la africana, a la asiática, a la australiana y a algunos países europeos que, a través de la colonización, han sido vulnerables e influenciables ante la imposición de una sola visión del mundo, de una sola cultura, de una sola historia; colonización que en sus inicios fue tan violenta que el horror y el miedo no dejaron otra opción que aceptarla, pero, a través del tiempo y del servilismo de quienes asumieron el poder, se fue reproduciendo mediante el adiestramiento, las instituciones, la literatura, la radio, la televisión, el cine y, actualmente, la internet, llevando a adoptarla, a asumirla y a adaptarse a ella hasta el punto de valorar y defender más lo ajeno que lo propio, a invisibilizar lo autóctono, a copiar y reproducir conocimientos y políticas que, más que beneficiar a la población en general, son cortinas de humo que ocultan los problemas estructurales que la afectan.

En este orden de ideas, y de acuerdo con Puigross (2017), la educación ha sido utilizada como instrumento de dominación, pues desde la llegada de los españoles como invasores de las tierras latinoamericanas, como se les conoce hoy, se impuso un modelo educativo fundamentado en un "educador" y en un "educando"; es decir, uno que enseña, quien dice cómo hacer las cosas y otro el que aprende, el que hace lo que el educador le dice que haga; momento en que una cultura sometió el conjunto de otras culturas, en que una fuerza ideológica y una fuerza discursiva se impusieron. En tal sentido, y como afirma la Comisión Económica para América Latina y el Caribe (CEPAL) (2011, citada en Cecchini, 2014):

la educación representa una de las principales herramientas de las cuales disponen los Estados para revertir la reproducción intergeneracional de la pobreza y las desigualdades, y desacoplar los orígenes sociales de los individuos de sus logros en términos de bienestar (p. 49).

De lo que se infiere que los sistemas de educación en América Latina están diseñados para reacomodar, para adaptar, para someter sutilmente a una sola cultura, la cultura que impone el capitalismo con su modelo neoliberal que homogeniza para que se piense igual, de acuerdo con lo impuesto, pero se actúe individualmente, fragmentando a la sociedad, excluyendo a grandes sectores de la población y discriminando colectividades. 
En este contexto se cuestiona y, al mismo tiempo, se desafía el escenario de la educación superior en la búsqueda de procesos de transformación social. Estos desafíos se comprenden desde la justicia educativa, entendida como la posibilidad de acceso con calidad a la enseñanza-aprendizaje de todos como consecuencia de prácticas individuales y acciones colectivas. A partir de este panorama, y desde una reflexión teórica, se intentan identificar los aportes que ofrece la perspectiva pedagógica y filosófica de la Uniclaretiana en su apuesta de educación superior de frontera, modalidad a distancia, con mirada humanista, liberadora, crítica y contextual, como respuesta a las aspiraciones que tienen aquellas comunidades que afrontan realidades de pobreza, exclusión, olvido y violencia sociopolítica, especialmente indígenas, afrodescendientes y campesinas, de acceder a una universidad que se ajuste a su contexto y dinámicas de vida.

No obstante, el hecho de ser una universidad inmersa en contextos de conflictos, de incertidumbres e influenciada y exigida por la institucionalidad, a pesar de que uno de sus postulados es "pretender ser ante todo 'vinculante', no 'institucionalizante'" (Fundación Universitaria Claretiana, 2013a, p. 430) hace difícil el desarrollo de este propósito, pues es condicionada por el modelo neoliberal, que influye en todas las dimensiones de la vida sin que dé espacio para la implementación de otras iniciativas, consideradas por este como contrarias a los intereses de quienes detentan el poder y, desde ahí, imponen políticas excluyentes, discriminatorias, que sumergen la mente en una sola visión de la historia, en una sola forma de ver el mundo.

La Uniclaretiana surge en el año 2006 como resultado de la experiencia del trabajo realizado por la Comunidad de los Misioneros Claretianos en la región del Pacífico colombiano, en la búsqueda de formar sujetos artífices de cambio que desencadenen procesos de emancipación personal y comunitaria. Su sede principal está ubicada en Quibdó, capital del departamento del Chocó, con cobertura nacional a través de los Centros de Atención Tutorial, llamados CAT, ubicados en diferentes ciudades del país.

\section{QUÉ SE ENTIENDE POR JUSTICIA EDUCATIVA}

Para entender el concepto de justicia educativa es indispensable hacer referencia a aquello que se concibe como justo e injusto. Muchos estudiosos de la justicia han coincidido en que es un valor intersubjetivo, dado que enfatiza en el saber y en el sentir compartido; en este sentido, Aristóteles sostenía, en su Ética nicomáquea, que la justicia es la virtud, punto medio 
entre dos vicios extremos, más alta y más perfecta de una persona cuando se le considera en relación con otras. Aducía, de manera general, que ser justo es la cualidad de obrar de acuerdo con las leyes cuando estas se encaminan hacia el bien común, de modo que se es "justo" cuando se aspira a producir o a conservar la felicidad de una asociación u organización política; pero, de manera particular, se refería a la justicia distributiva que implicaba proporcionalidad, es decir, mirar y reconocer al otro como igual en cuanto se es ser humano y diferentes al mismo tiempo, pues cada quien tiene sus particularidades; y, a la justicia rectificatoria, que suponía recuperar la igualdad alterada por un delito o por el incumplimiento de contratos (Libro V, citado por Nino, 1993, p. 66).

Así mismo, Platón, en La República, ratificaba que la justicia es la parte esencial del bienestar, contrastando que el hombre injusto manifiesta una contradicción entre sus valores, haciéndolo impotente para obrar en reyerta y discordia consigo mismos y sus acciones hacia los demás, y lo hace tan enemigo de sí mismo como de los justos lo que ocasiona discrepancias, odios y luchas. Sostenía que la capacidad injusta de algunos hombres impide que actúen en común con otros, haciéndolos incapaces de ser felices (Libro Primero, 352-354, citado por Nino, 1993, pp. 65-66) y de hacer que otros satisfagan necesidades y oportunidades fundamentales de la vida humana. En síntesis, estos dos filósofos coincidieron en que la justicia es un valor que enaltece a la persona en su accionar, siempre y cuando tenga en cuenta el bienestar o la felicidad del otro.

En contraposición, Rawls (1971) sustentaba que la justicia es la primera virtud de las instituciones sociales, de ahí que este valor juega un papel en la cooperación social, cuyo objeto primario está en la estructura básica de la sociedad, quiere decir, en el modo en que las grandes instituciones sociales establecen los derechos y deberes fundamentales y acuerdan la división de los beneficios y obligaciones provenientes de esa cooperación social, por lo cual, la concibe como imparcialidad, trascendiendo el concepto tradicional del contrato social, dado que cada persona posee una inmunidad fundada en la justicia que ni siquiera el bienestar de la sociedad en conjunto puede atropellar, razón por la cual el ser justo niega que la pérdida de libertad para algunos se vuelva justa por el hecho de que un mayor bien es compartido por otros. Sin embargo, admite que su planteamiento no riñe con la noción tradicional, puesto que comparte el sentido más específico que Aristóteles da a la justicia, en razón de no obtener para sí mismo cierto beneficio apoderándose del actuar de otros o negándole a una persona lo que le corresponde, 
aclarando que su concepto está pensado para aplicarlo a las instituciones de manera general. En suma, la justicia es concebida como un valor que enaltece a la persona, a las relaciones que se establecen entre ellas y a las prácticas de las instituciones.

En concordancia con estas dos perspectivas, Echeverry y Jaramillo (2006) sostienen que una teoría de la justicia debe contemplar, además de los derechos y libertades individuales, el reconocimiento, la identidad, los objetivos comunes y los proyectos solidarios; pero también la soberanía nacional, la autodeterminación de los pueblos y el respeto por el medio ambiente, aspectos que trascienden la visión liberal de autonomía personal, de libertad individual, hacia la noción de comunidad, de procesos y acciones colectivas, en la cual se formen sujetos activos, lo que implica luchas constantes entre el individuo y la estructura, permitiendo cambios sociales y culturales; en otras palabras, la justicia es un compromiso que deben asumir las personas individual y colectivamente, pues son estas las que hacen a las instituciones, no desde la dependencia, ni para apropiarse, ni para anularle, sino desde la solidaridad y la reciprocidad, desde la unión como un engranaje en el que cada uno cumple una función igual de importante, una misión que hace posible que entre todos construyan la sociedad justa. De acuerdo con lo expuesto anteriormente, se deduce que la justicia es un término que, dependiendo de la percepción que se tenga del mundo adquiere sus significados; es decir, lo que para unos es justo para otros puede ser injusto; no obstante, se concuerda en que es una cualidad que engrandece, un valor, un ideal de lo que deberían ser las instituciones y el comportamiento de hombres y mujeres en busca del bien común, lo que permite tener un motivo para caminar hacia un propósito, pues no da cuenta de la realidad.

Y ¿cuál es la realidad? He ahí lo paradójico de lo justo, lo injusto de un sistema centrado en la acumulación de riqueza y la tenencia del poder sin importar si se destruyen vidas, culturas y el medio ambiente. Lo injusto de un modelo económico sustentado en la flexibilización, que se sintetiza en la pérdida de derechos laborales, económicos, sociales, culturales, ambientales, de asociación, ciudadanos, supuestamente, para facilitar la eficiencia económica como la única forma digna de obtener el máximo bienestar social; la privatización, que pone en manos de particulares, o sectores, la economía de un país quitándoles el derecho tanto al Estado de proteger a su ciudadanía como a esta para el acceso con calidad a bienes y servicios; el libre mercado, que elimina los impuestos a las importaciones para abrir el ingreso y funcionamiento del capital extranjero, en otras palabras, la ex- 
pansión de las multinacionales sin ninguna restricción. Un sistema que, en palabras de Monedero (2016), ha sumergido a la sociedad en burbujas culturales manteniéndola resignada y convencida de las verdades incuestionables que imponen los políticos, los financieros y los grandes empresarios, donde no se encuentra el sentido colectivo de las cosas porque la ha enajenado y le ha impuesto, a través de los medios de comunicación y las instituciones, un sentido común, caracterizado por el individualismo, la desconfianza ante el otro, los cuestionamientos a aquellos Estados que no obedecen lineamientos imperiales, las controversias de lo público y de lo social, la justificación de las desigualdades; donde se gobierna con violencia para que el miedo impida resistencia, con leyes y reformas que benefician a unos pocos; donde impera la corrupción, la represión, el narcotráfico, el terrorismo y la mercantilización de todas las dimensiones de la vida.

Un sistema injusto que reproduce y justifica las desigualdades sociales, en el cual la escuela es el reflejo de la sociedad en todos sus ámbitos. Todo lo que se evidencia en las relaciones escolares entre pares o docente-estudiante y viceversa es una radiografía del contexto familiar y sociocultural de cada uno de los individuos. De ahí la importancia de la escuela, porque es donde confluye toda la diversidad; es en la escuela donde se pueden comenzar procesos transformadores para la convivencia y que pueden transcender el ámbito social. Si se lograra que en el ambiente escolar se mire al individuo, no como un número más sino como un ser humano, con una historia y una experiencia que lo hace comportarse como lo hace, que puede transformarse a través de las condiciones apropiadas que se le generen, seguramente será un sujeto capaz de cambiar y ver reflejado en el otro no a su enemigo, sino a quien en medio de sus diferencias lo complementa. Sin embargo, y en avenencia con lo planteado por Dussel (2004), a la escuela se le pide más que socializar saberes y vivencias desarrollar programas y estrategias para cumplir con unos requerimientos establecidos por directrices nacionales e internacionales de escolarización para la inclusión educativa, por lo cual surgen propuestas que, en muchos casos, pueden producir procesos de retorno a las aulas escolares; pese a los esfuerzos, no resuelven la situación de vulnerabilidad en el corto y mediano plazo, porque se dan en una sola dimensión y en poblaciones focalizadas, teniendo en cuenta que el problema de vulnerabilidad es multidimensional.

En este orden de ideas, Rivas (2012) habla, específicamente, de dos causas generadoras de las desigualdades educativas que, a la vez, son dos posibles caminos de solución: una es la distribución de la riqueza y dos la 
revisión de las pedagogías. En relación con la primera, afirma que América Latina es la región más desigual de la tierra, pues se vive entre la opulencia y la miseria; indica que mientras el diez por ciento de los más ricos de la población poseen el cincuenta por ciento de los ingresos, los más pobres solo tienen el uno por ciento, agregando que son a estos a los que más se les cobra impuestos, por tanto, hay que hacer visibles esas tributaciones. En cuanto a la segunda causa, demuestra que se halla dentro de las escuelas, es decir, en las formas en que se enseña y se aprende; en tal sentido, menciona tres modelos de sistemas educativos y tres modelos de pedagogías que rigen en la mayoría de los países:

1. El Sistema Educativo Germano, implementado en Alemania, Austria y Suiza, cuya pedagogía está direccionada a la separación de los alumnos, consistiendo en una escuela primaria común de corta duración que al finalizarla y tras un examen son separados: unos van a las escuelas técnicas vocacionales con el propósito de ser preparados para el trabajo manual y los otros van a escuelas académicas como paso a la universidad, enfocados al trabajo intelectual.

2. El Sistema Educativo de los Países Nórdicos, aplica para Dinamarca, Noruega, Suecia y Finlandia. En este la modalidad utilizada es la integración personalizada, que consiste en una educación común de largo tiempo, con enseñanza individualizada similar en todas las escuelas integrándolas socialmente, lo que permite enseñar pensando en cada alumno, pues su norma es el individuo.

3. El Sistema Educativo Latino, heredado de Francia y que se aplica en los países latinoamericanos; en él se cursa una escuela común de mucho tiempo, al igual que en los países nórdicos; sin embargo, su pedagogía es diferente puesto que está fundamentada en la norma, en la enseñanza igualitaria, homogénea y uniforme para todo un grupo de alumnos. Al finalizar el año escolar se deben realizar pruebas para medir los aprendizajes y clasificar a los estudiantes, en las cuales, si no se alcanza el nivel establecido, se tendrán que repetir los mismos contenidos vistos el año anterior. Este modelo educativo está basado en una pedagogía conocida como el método simultáneo, que consiste en enseñar exactamente lo mismo, al mismo grupo de alumnos y en todo el sistema edu- 
cativo, lo que ocasiona una gran disyuntiva a la docencia y es el de hacer repetir o avanzar de año escolar al alumno, dependiendo de su rendimiento académico o sin los aprendizajes.

Es en este contexto en el que se forja el concepto de justicia educativa, entendida como "un modelo que delinea un plan de una acción posible orientada a construir una escuela mejor y más justa" (Veleda, Rivas y Mezzadra, 2011, p. 8). Estos autores afirman que la escuela es un sistema y que no es posible solucionar sus problemas multiplicando los dispositivos especiales para los niños menos favorecidos; argumentan que la escuela debe ser una facultad y no un dispositivo de la lucha contra la pobreza, esta es esencial pero debe estar a cargo de otras instituciones; la escuela es un sistema y es el sistema mismo el que debe ser objeto de la política, por lo cual, la política educativa no es solamente una cuestión de medidas técnicas, debe ser consecuencia de los principios de justicia elegidos por una sociedad.

Al respecto, y continuando con lo expuesto anteriormente por Rivas (2012), hay dos caminos que pueden llevar a la construcción de la justicia educativa: el primero es hablar de pedagogías en las aulas y en los pasillos de las escuelas, mirar la educación desde la perspectiva de los estudiantes, lo que implica salir del sentido común de la pedagogía impuesta, visitar las aulas de otros docentes, capacitarse, revisar y aprender de otras pedagogías, filmar, mirar y comentar las propias clases, personalizar la enseñanza, que el docente, cuando esté preparando su clase, piense en cada uno de sus estudiantes, en sus nombres, en sus caras, en sus características particulares, no en el grupo, ni en la norma general, sino que individualice su pedagogía. Y el segundo camino es la distribución equitativa de la riqueza, es decir, que se les exija a los grandes contribuyentes y a la gran empresa el pago de impuestos de acuerdo con sus ganancias y no solo a las grandes mayorías, para revertirlos en la extensión de la jornada escolar para ampliar los alcances de expresión del estudiantado. En síntesis, según Rivas (2012), los dos caminos para construir la justicia educativa son las reformas pedagógicas y las reformas impositivas; de lo que se infiere que la justicia educativa es posible lograrla sin afectar el estado de las cosas en el que se está inmerso.

Por otro lado, la justicia educativa no puede ser concebida sin la justicia económica y sin la justicia social. De acuerdo con Rosa María Torres (2005), lingüista y pedagoga ecuatoriana, la justicia educativa se entiende como "iguales oportunidades de educación y aprendizaje a lo largo de toda la vida para todos" (p. 14); arguye que esta justicia educativa solo puede ir 
de la mano de la justicia económica, entendida como la "satisfacción de las necesidades básicas de toda la población, entre ellas la propia educación" (p. 14). Objeta que:

Las condiciones para hacer efectivo [o no] el derecho al aprendizaje de todos no tiene que ver únicamente con la política educativa, sino y, sobre todo, con la política económica y la política social en su conjunto [dado que] "las políticas" - y la política educativa concretamente- se plantean como medidas macro con efectos esperados a mediano y largo plazo, mientras que las necesidades y las expectativas de la gente se juegan en lo inmediato, con plazos que no pueden esperar (p. 107).

Sostiene que la realización del derecho a la educación debe ser progresiva, de ahí el gran significado que tiene la universalización de la educación básica de calidad que, en su sentido amplio, es una educación capaz de satisfacer necesidades básicas de aprendizaje de niños, niñas, jóvenes y adultos dentro y fuera del sistema escolar, y a lo largo de toda la vida (Torres, 2005).

En esta dirección, y después de hacer un balance del estado de la educación pública en América Latina, Torres (2005) propone doce tesis para el cambio educativo: 1) del alivio de la pobreza al desarrollo, 2) de la educación como política sectorial a la educación como política transectorial, 3) del predominio de los criterios económicos a una visión integral de la cuestión educativa, 4) de la ayuda internacional a la auténtica cooperación internacional, 5) de la escuela a la educación, 6) ddel derecho a la educación al derecho a una buena educación, 7) del derecho al acceso al derecho de aprendizaje, 8) del derecho al aprendizaje al derecho de aprendizaje a lo largo de toda la vida, 9) de la escuela a la comunidad de aprendizaje, 10) de la capacitación docente a la cuestión docente, 11) de la educación básica como educación escolar a la educación básica como educación ciudadana y 12) de adecuarse al cambio, a incidir sobre el cambio. En estas tesis destaca la necesidad de una formación general que se ha ido aplazando en pro de una especialización que prioriza educar para el trabajo, y reivindica una educación que potencie la capacidad transformadora, que prepare para anticipar el cambio, controlarlo y orientarlo hacia la construcción de otro mundo posible en el que prevalezca la justicia, la dignidad, la democracia y la paz.

Con base en lo expuesto, la justicia educativa puede interpretarse como la realización del derecho al conocimiento que tienen todas las perso- 
nas, por el solo hecho de ser seres humanos, lo que implica, necesariamente, la lucha por políticas incluyentes que brinden oportunidades que el sistema capitalista, con su modelo neoliberal, no garantiza. Al igual que el concepto de justicia, el de justicia educativa también puede considerarse como una aspiración, como un propósito por el que hay que trabajar arduamente, desde la acción individual, para constituir la acción colectiva, que es la que incide no solo en la toma de decisiones, sino también en el reconocimiento, en la autodeterminación, en la garantía de los derechos y en hacer realidad los sueños, acercándose a los ideales propuestos.

\section{LA EDUCACIÓN COMO MECANISMO COLONIZADOR O EMANCIPATORIO}

En concordancia con Puigross (2017), América Latina tiene una historia en común, una historia caracterizada por un antagonismo instalado en el instante mismo en que fue utilizada la cruz para evangelizar y la espada para exterminar a los nativos de estas tierras; en el momento en que se les leyó a los indígenas, en una lengua desconocida para ellos, que debían "evangelizarse y aceptar la autoridad de los conquistadores a riesgo de perder su vida y sus bienes" (Puigross, 2017, prr. 4). Afirma la autora que esta es "la escena fundadora de la educación latinoamericana", puesto que en ese momento se percibió un "educador", persona que tiene cultura legítima, y un "educando", aquella o aquel que no tiene cultura, por lo cual es despreciado (Puigross, 2017); momento en que una cultura se impuso sobre otras, en que una fuerza ideológica y una fuerza discursiva dominaron.

Latinoamérica ha sido un territorio en el que se han desencadenado constantes luchas, desde Simón Rodríguez en el siglo XVIII, que promovía la escuela pública y la educación popular, enfatizando en la emancipación, hasta las confrontaciones estudiantiles por el derecho a la educación en el siglo XXI, entre los gobiernos para imponer políticas hegemónicas y el pueblo para romper con esas cadenas que lo han sometido durante siglos, pues en palabras de Pablo Adrián Imen (2017), la educación es pensada como un terreno en disputa, en el cual se confrontan diferentes lecturas que caracterizan los sistemas educativos, sus dinámicas institucionales y sus prácticas pedagógicas, entre las que se encuentran: la que plantea que el sistema educativo es una institución reproductora de relaciones de poder asimétricas opresivas, la foucaultiana, la vertiente liberal que sostiene que el sistema 
educativo es el ámbito de la realización de la ciudadanía, y la democracia y la corriente dialéctica que conciben el sistema educativo como una red de instituciones y relaciones sociales que disputan en sentidos o emancipadores o reproductores del orden. Así, de acuerdo con los intereses que se tengan, ya sean colectivos o particulares, se educa para emancipar o para someter. En el sistema capitalista la educación está siendo utilizada para someter a una sola forma de concebir el mundo, a imitar o copiar una sola forma de vida, dejando de lado otras vivencias, otras formas de ver y sentir la realidad, otras lógicas, de ahí que es imperativo plantear alternativas comunes para hacer frente al monstruo del colonialismo.

Sin embargo, la educación también puede ser "una poderosa herramienta para avanzar hacia sociedades más inclusivas y democráticas" (Krichesky, 2016), siempre y cuando los sistemas educativos permitan, por un lado, la movilización social para la exigibilidad de derechos, y por el otro brindar una educación de calidad para todos sin diferencia de sexo, raza, edad, estratificación social, espacios geográficos, discapacidad, como requisito necesario para el logro de la igualdad y la justicia social; una educación liberadora basada en el reconocimiento y en el respeto a los saberes que nos han constituido como comunidad, como nación, a nuestras lenguas, nuestra historia y nuestras tradiciones, nuestras comprensiones y macro visiones acerca del mundo y de la sociedad (Gentili, 2009, p. 55), un diálogo y articulación de saberes de otras historias, historias contadas y escritas por quienes las viven, por quienes sufren y gozan los acontecimientos, los hechos, los procesos y no por muchos historiadores que alimentan los intereses de determinadas culturas para someter a otras; una educación inclusiva que invite, en palabras de Skliar (Universidad Nacional Abierta y a Distancia, 2014), a una ética de lo singular.

\section{LA EDUCACIÓN EN COLOMBIA}

Colombia no es la excepción. Desde 1810, año en que inició el proceso independentista, según Herrera e Infante (2004), se vio la necesidad de organizar un sistema educativo que enseñara el ideario de lo nacional y se promoviera la identidad en la población, mediante los símbolos y las imágenes de los patriotas destacados en la época. Estas características se mantuvieron hasta los años treinta del siglo XX, cuando cayó la hegemonía conservadora, generando algunos cambios, como: 
Control de la educación por parte del Estado; extensión de la cobertura educativa — por lo menos en el nivel de primaria—; creación de campañas educativas dirigidas al campesinado — como la Campaña de Cultura Aldeana-, o a los sectores urbanos trabajadores — como las escuelas por correspondencia-; la consolidación de la formación de maestros — caracterizada por la fundación de la Escuela Normal Superior-, entre otros (p. 79).

Sin embargo, y siguiendo a estos dos autores, estas reformas duraron hasta 1946, cuando los conservadores retomaron el poder y la iglesia recuperó el control de la educación. A partir de los años cincuenta, en el contexto de la industrialización, el sistema educativo se orientó hacia la formación de una clase calificada técnicamente para responder con esa exigencia internacional; posteriormente, en los años setenta se postuló la educación universal como vía para el acceso a la ciudadanía y a los valores culturales de la modernidad, lo que implicó un sistema educativo centralizado, un currículo único, la confianza en el rol de la educación como mecanismo de ascenso social, de acceso a los bienes materiales y simbólicos y la preparación del recurso humano como garantía para el desempeño laboral. No obstante, algunos movimientos sociales de estudiantes y maestros se opusieron a este modelo educativo, proponiendo prácticas pedagógicas y teorías educativas alternativas, esfuerzos y conquistas que se iniciaron desde los sesenta y perduraron hasta los setenta (Herrera e Infante, 2004).

En los años ochenta, como preparación para la implementación del modelo neoliberal, comenzó el desmonte de todos esos derechos ganados, camino hacia el proceso de la mercantilización educativa. Es así como desde la década del noventa, independientemente que en Colombia se estuviera instituyendo la Constitución de 1991 en busca del Estado Social de Derecho, la política educativa se ajusta al nuevo orden mundial que exigía, y en lo que va del siglo XXI lo sigue exigiendo más que nunca, la privatización de todos los derechos. En tal sentido, y como lo expresan Herrera e Infante (2004) la política educativa se centró en aspectos como:

Avanzar en la descentralización, promover competencia entre instituciones públicas y privadas para obtener mejor educación, crédito para financiar estudios universitarios, integración de colegios, establecer el sistema nacional de evaluación de la calidad de la educación primaria y secundaria — con base en pruebas cognitivas aplicadas por PISA anualmente a los estudiantes-, reestructurar las facultades de 
educación y las escuelas normales, establecer el examen básico universitario como medio de evaluación para todas las carreras, hacer reconversión de bachilleratos técnicos en académicos, reestructurar el estatuto docente para flexibilizar el movimiento de los trabajadores, entre otros, fueron propuestos por primera vez en el plan Gaviria y se fueron cristalizando en los posteriores gobiernos (p. 82).

De lo que se infiere que la educación ha obedecido a directrices hegemónicas que aliena, para mantener el statu quo, buscando adiestrar hacia la repetición de un mismo discurso o la imitación de un solo modelo, camino a la eficiencia económica, al emprendimiento y a la gerencia, dejando de lado la formación de personas pensantes, críticas, activas y transformadoras de realidades, de ahí la injerencia de los organismos financieros internacionales: Fondo Monetario Internacional (FMI), Banco Mundial (BM), Organización Mundial del Comercio (OMC) y el Banco Interamericano de Desarrollo (BID) en el diseño de las políticas educativas en el ámbito mundial.

En este orden de ideas, dentro de los principales desafíos que enfrenta la política pública de educación en Colombia está, fundamentalmente, el hacer frente al problema de la exclusión y a la tendencia de moldear y homogenizar para lo gerencial, buscando una educación inclusiva que brinde calidad y, sobre todo, reconocimiento del otro como iguales y diferentes al mismo tiempo, en palabras de Skliar (citado en Universidad Nacional Abierta y a Distancia, 2014), "incluir es mirar al otro u otra como cualquiera con gesto de igualdad para establecer una conversación", no para recitar discursos y repetir una sola historia, sino para intercambiar saberes, para dialogar, para conocer otros relatos, porque la inclusión requiere de participación activa, de existencia, de preguntas con respuestas; por lo tanto, es necesario $\mathrm{y}$ urgente trabajar por iniciativas comunes direccionadas hacia una ruptura con la institucionalidad, en la medida que esta se fundamente en la injusticia social y promueva la marginación y la exclusión, en que su perspectiva sea solo técnica e instrumental en función de lo económico, para abrir paso a otras visiones del mundo en aras de formar personas pensantes, creativas y, sobre todo, respetuosas de la vida.

\section{LA FUNDACIÓN UNIVERSITARIA CLARETIANA, UNICLARETIANA}

Dado el escenario anterior, en el año 2006 nace en Quibdó una propuesta educativa, como resultado de la experiencia del trabajo realizado 
por la Comunidad de los Misioneros Claretianos en la región del Pacífico colombiano, en respuesta a las realidades de pobreza, exclusión, olvido y violencia sociopolítica padecidas por las comunidades, especialmente, indígenas, afrodescendientes y campesinas, fundamentada "en la garantía de los Derechos Humanos, el pensamiento crítico-social, la autonomía, la solidaridad y la lectura permanente de las realidades micro y macro sociales, económicas, políticas y culturales, en aras de posibilitar escenarios de vida digna sostenibles" (Fundación Universitaria Claretiana, 2013a, p. 13). Se define como una Institución de Educación Superior (IES) de frontera, dada su presencia en territorios vulnerables, con modalidad a distancia y presencial, sin exclusiones sociales ni religiosas, proyectada a "formar profesionales con capacidades de transformar la realidad, mediante la participación activa de los miembros de la comunidad, basándose en el respeto por la diversidad étnica, cultural, social, económica, política y de género; con sentido crítico, ético y estratégico" (Fundación Universitaria Claretiana, , 2013a, p. 9), "sin que implique salir de su contexto para poderse formar a nivel profesional, facilitando que sea la universidad la que se desplace hacia la gente y no a la inversa" (Uniclaretiana, 2013, p. 11).

En tal sentido, en el año 2007, con la obtención del registro calificado para los programas de Antropología, Teología, Licenciatura en Educación Religiosa y Trabajo Social, se da a conocer públicamente, a través del foro "Territorio y Educación en el Chocó", como reflexión sobre el papel que juega la educación superior frente a los impactos de la normatividad vigente y los efectos del conflicto armado por la tenencia y uso de los recursos naturales en el Pacífico (Fundación Universitaria Claretiana, 2007-2008). En el año 2010, obtuvo el registro para la Especialización en Métodos y Técnicas en Investigación Social y la Especialización en Estudios Bíblicos, en la modalidad a distancia y virtual. En el 2014 crea un nuevo CAT en Pereira, para cubrir la región del Eje Cafetero y actualmente cuenta con otros en la Región Caribe, como son: Bosconia, departamento del Cesar, Sincelejo, departamento de Sucre y Uribia, departamento de La Guajira, ofreciendo el Programa de Trabajo Social. Cuenta con más de mil quinientos estudiantes y con nuevas especializaciones, entre ellas Gerencia de Servicios Sociales y Gestión en Procesos Psicosociales, modalidad a distancia; además, en su sede principal, Quibdó, implementó la modalidad presencial con los programas de Psicología e Ingeniería Industrial e Ingeniería de Sistemas. 


\section{Misıón Y Visıón}

La Uniclaretiana como IES de frontera se ha comprometido con la formación integral para brindar capacidad de saberes a aquellas personas que, por sus condiciones de vida y laborales, les ha sido difícil acceder a un centro universitario, por lo cual está en permanente búsqueda de nuevos conocimientos con alto sentido humanístico, para que los hombres y mujeres que accedan a ella sean

promotores del equilibrio ecológico, competentes en la práctica científica y humanística, éticos en su conducta, respetuosos de la dignidad humana y la equidad de género, sensibles y responsables ante la situación social y reconocedores de la diferencia, para que sean gestores de cambio con justicia social, desarrollo humano y paz (Fundación Universitaria Claretiana, 2013a, p. 7).

De esta manera, contribuirá a que su comunidad educativa, en cualquiera de los contextos en donde se encuentre, participe activamente de los cambios que se requieran para superar las problemáticas sociales, siendo ética, idónea, sensible, responsable y comprometida; obviamente, se trata de unos perfiles exigentes que, en buena medida, son para hacer diferencia frente al mundo de ofertas académicas, y aún más si se agrega que sus estudiantes deben tener como valores "el respeto por la dignidad humana y la diversidad, la libertad de pensamiento, la justicia como fundamento de la paz, el diálogo intercultural, la solidaridad; y, como principios de participación la democracia y el pluralismo" (Uniclaretiana, s. f., p. 18).

De acuerdo con lo anterior, y dentro de su concepción, busca ser una universidad que mediante sus programas de pregrado y posgrado forme profesionales con calidad humana y alto grado de compromiso social, dotando de una conciencia crítica y creadora que permita ser propositivos y actuar de acuerdo con la realidad de cada entorno. No obstante, el hecho de estar inmersa en una sociedad donde el centro de toda actividad es el mercado, hace que se aleje o se le dificulte cumplir con este propósito.

\section{Proyecto Educativo Institucional (PEI)}

De acuerdo con el Modelo Pedagógico de la Fundación Universitaria Claretiana (s. f.), esta institución ha ido construyendo el marco de re- 
ferencia de su Proyecto Educativo Institucional (PEI) que no solo tiene en cuenta y se ocupa de los elementos institucionales universitarios en relación con el campo investigativo, docente y de proyección, sino que va más allá, proponiendo una visión y misión que establecen su actuación pedagógica y su intención de formar profesionales para un país caracterizado por sus contradicciones históricas y por esa realidad que lo hace problemático. En consecuencia, plantea que este modelo no solo responda por los procesos de enseñanza, aprendizaje y evaluación del conocimiento y los saberes, sino que, además, le apueste a la transformación social, a la búsqueda de la justicia, a la construcción de un ser humano distinto capaz de afrontar y cambiar la realidad impuesta por un modelo económico que carcome y que ha demostrado su incapacidad para resolver los problemas que aquejan a esta sociedad, aumentando las grandes desigualdades y el irrespeto por la dignidad humana y por la naturaleza.

De ahí que, la Fundación Universitaria Claretiana (s. f.) define su modelo pedagógico como construccionista social, dado que se asume como praxis, pues propone elementos tanto para la formación teórica como para la acción educadora, lo que implica la reconstrucción del mismo discurso y la acción formativa, sin dejar de lado que se realimente y se resignifique de acuerdo con circunstancias históricas y de contextos, ya que la educación no debe ser una cuestión estática sino un hecho dinámico, flexible, contextualizado que puede incluir acuerdos y reformas en determinadas situaciones. Es un modelo aprobado por

la pedagogía social, los paradigmas crítico-sociales y los planteamientos histórico-culturales hermenéuticos; es inminentemente cualitativo, cuestionador, contestatario y afirma sus raíces en la experiencia de los Misioneros Claretianos en el mundo, su experiencia educadora en el encuentro con las comunidades, recogiendo la voz de Lev Vigotsky, nutriéndose permanentemente de Paulo Freire y haciendo realidad las nuevas tendencias y modalidades educativas de las tecnologías de la información y la comunicación.

Este modelo de constructivismo social se implementa desde tres modalidades: a distancia, virtual y presencial, proponiendo llegar a donde otras instituciones no llegan, pretendiendo acompañar y crecer con la comunidades marginales, optando por el pobre, por el excluido, por las víctimas del sistema, de la guerra y de la desigualdad social (Fundación Universitaria Claretiana, s. f., pp. 4-5). 
De lo que se deduce que la perspectiva filosófica y pedagógica de esta IES está enmarcada dentro del concepto de justicia educativa, pues en su concepción plantea una alternativa al modelo de enseñanza-aprendizaje impuesto por el modelo neoliberal, que ubica en el centro de toda actividad humana al mercado, a la acumulación de capital, convirtiendo así a la educación en un servicio por el que se debe pagar. No obstante esta perspectiva, en la medida en que se consolida el modelo económico se complica su materialización, dado que el medio absorbe y quien no se acoja a él tiende a desaparecer, lo que requiere de voluntad política para hacer frente a ese contexto en que se debate el presente y futuro de la educación en América Latina y el Caribe, desafiando decisiones de sumar esas filas de universidades con propuestas alternativas en el continente o sustraerse del arribo de la educación neoliberal.

\section{LA PERSPECTIVA PEDAGÓGICA Y FILOSÓFICA DE LA FUNDACIÓN UNIVERSITARIA CLARETIANA DESDE EL CONCEPTO DE JUSTICIA EDUCATIVA}

La sensibilidad en la perspectiva pedagógica y filosófica de la Fundación Universitaria Claretiana como IES de frontera cobra relevancia cuando, en su visión y misión, como Misioneros Claretianos, plantean cuatro elementos que la ubican dentro del concepto de justicia educativa. Estos elementos son:

1. Lo crítico-social, en cuanto busca potenciar "la conciencia crítica, profética, humanizadora y personalizadora como un elemento fundamental para alcanzar la transformación de las estructuras sociales y, por ende, la renovación de los contextos y culturas desde la óptica de la justicia, la equidad y el fomento de la dignidad" (Fundación Universitaria Claretiana, 2013b, p. 12).

2. Lo contextual, dado que propone "estar en diálogo permanente con el contexto local, nacional e internacional. Un teólogo de la FUCLA nunca podrá ser ciego a la realidad social y política que envuelve su momento histórico" (Fundación Universitaria Claretiana, 2013b, p. 32).

3. Lo liberador, porque "se enmarca en las corrientes teológicas que en los últimos cincuenta años predominan en América Latina. 
Una o un profesional de la FUCLA no podrá ser nunca indiferente a la discriminación, la exclusión, la opresión, la ecología, etc." (Fundación Universitaria Claretiana, 2013b, p. 32).

4. Lo intercultural, ya que señala que "la Teología de la FUCLA es intercultural, porque parte del diálogo de saberes, del diálogo inter-religioso y del respeto a la subjetividad en los sujetos" (Fundación Universitaria Claretiana, 2013b, p. 32).

En tal sentido, los anteriores elementos que hacen parte del PEU de Teología, programa misional de la Uniclaretiana, recoge un importante legado histórico de la Teología de la Liberación en Latinoamérica, poniéndolo en diálogo con las nuevas realidades y subjetividades y es lo que le da consistencia a su perspectiva pedagógica y filosófica desde el concepto de justicia educativa.

En términos de accesibilidad, la Uniclaretiana ha realizado aportes significativos en su corta trayectoria, en la medida que ha logrado materializar su propuesta de universidad de frontera, reconociendo este acceso no solo en términos de facilitar el ingreso a partir del precio y la modalidad, sino en llegar a regiones periféricas del país donde no existe otra oferta educativa y brindar las condiciones necesarias para que las personas que ingresan puedan desarrollar su proceso de formación en el contexto que viven. Tal como lo afirma su Plan de Desarrollo: la Uniclaretiana, como una institución de frontera, en el sentido de facilitar el acceso a aquellas personas que no disponen de las mejores condiciones para acceder a los beneficios de la educación superior, le implica asumir una serie de compromisos que, por su dimensión y trascendencia, demandan de sus estamentos una exigente labor y una responsabilidad de primer orden (Uniclaretiana, 2013b, p. 47).

No obstante, son varios los desafíos que se tienen en este sentido y que pueden apuntar a fortalecer el concepto de justicia educativa con los principios que esta desarrolla. En primer lugar, las capacidades del personal docente deben tener correspondencia con el tipo de estudiantes de una universidad con las características de la Uniclaretiana, cuya población objeto son personas indígenas, afrodescendientes, mujeres cabezas de hogar, campesinas, pueblerinas; es decir, se deben tener competencias en etnoeducación que faciliten la pedagogía y la didáctica. En segundo lugar, es indispensable contar con procesos de nivelación para que el acceso a la educación pueda estar acompañado de calidad y de formación de profesionales íntegros. 
Por otro lado, existen condiciones externas a la universidad que dificultan dar continuidad a su propuesta; estas son de índole económica y social, reflejo del modelo económico colombiano y de la formación geográfica y política. De acuerdo con lo anterior, es importante tener en cuenta que Colombia aún preserva un carácter centralizador en su política, y esto se refleja territorialmente en los niveles de desarrollo y servicios que hay para el centro y la periferia del país.

Otro elemento que la Uniclaretiana aporta al concepto de justicia educativa es el aprendizaje situado, que describe los procesos en los que ya intervienen los factores contextuales, siendo construido un conocimiento en relación con las situaciones de la vida real. Este elemento pedagógico es esencial en la construcción del Programa de Trabajo Social, lo cual se refleja en la estructura curricular propuesta, particularmente en la inclusión del tema intercultural y diverso, de tal forma que está dirigido a conectar la actividad del programa con las condiciones de los sujetos y comunidades a quienes va dirigido, que a partir de sus procesos sociales de organización han ido exigiendo un mayor manejo conceptual y metodológico sobre sus procesos de identificación en las comunidades.

\section{CONCLUSIONES}

En la perspectiva pedagógica y filosófica de la Uniclaretiana, desde el concepto de justicia educativa, está la apuesta de su Programa de Trabajo Social, que surgió como consecuencia de la consolidación del conocimiento y el saber construido por los Misioneros Claretianos en la región del Pacífico colombiano, como opción de profundización del compromiso con la transformación de las realidades sociales, mediante el fortalecimiento de la capacidad de protagonismo, participación y organización de sujetos y comunidades regionales que aportan a una visión de desarrollo social endógeno, basado en la garantía de los derechos humanos, el pensamiento crítico-social, la autonomía, la solidaridad y la lectura permanente de las realidades micro y macro sociales, económicas, políticas y culturales en aras de posibilitar escenarios de vida digna sostenibles. Un trabajo social fundamentado en la construcción de paz con justicia social.

Sin embargo, la Uniclaretiana desarrolla su propuesta con sujetos que padecen los conflictos estructurales, tales como el conflicto armado o los propios inspirados en la injusticia social a los que se suma una política pública educativa en Colombia que no se plantea transformaciones sustan- 
ciales y que, además, tiene una carga colonizadora y desarrollista. En este sentido, el cuerpo docente de la universidad que no es formado por la Uniclaretiana también se rige por los preceptos y prácticas institucionales que, al final, se traducen en las informaciones que trasmiten a los estudiantes, que en muchos casos, como lo denominó Freire, son "bancarias".

De allí la necesidad, a manera de conclusión-recomendación, de fomentar nuevas miradas desde una epistemología contextual transformadora, en el caso de Colombia desde el sueño de paz que se está construyendo, que debe pasar primero por la formación o entrenamiento de los docentes en el espíritu crítico y transformador científico que desea impulsar la universidad; lo que significa que, para lograr cambios desde el estudiante en una relación de educación-justicia social, es fundamental que la planeación estratégica se acompañe de la formación de un cuerpo de docentes cualificado y propositivo que integre contexto-currículo-bases transformadoras; sin embargo, no es un asunto que se resuelve frente al computador, sino que debe ser praxis de vida y de cambio de realidades. Por otra parte, la continua integración de experiencias educativas transformadoras en Colombia y América Latina, "Nuestra América", debe reflejarse en la incidencia política para el cambio de políticas públicas educativas, acorde con los procesos transformadores surgidos desde las bases. Y de manera horizontal y constructiva, promover la organización del estudiantado desde los saberes integrados a los procesos de cambio.

El modelo de educación a distancia B-learning ha jugado un papel crucial como factor estratégico en el camino de acondicionarse a la vida de las personas, en contrarrespuesta a la academia tradicional que exige que sean las personas las que se adapten al sistema educativo, lo que permite que las personas que se vinculan a la Uniclaretiana no tengan que abandonar sus contextos.

Una de las limitantes que impide caminar hacia este propósito es que se debe tener en cuenta que el personal que ingresa a la institución, llámese estudiante, docente y administrativo, ha sido formado dentro de ese sistema educativo institucional, que implica una carga de educación colonizadora, contra la cual se enfoca el esfuerzo de la propuesta emancipadora de la Uniclaretiana. 


\section{REFERENCIAS}

Cecchini, S. (2014). Educación, programas de transferencias condicionadas y protección social en América Latina y el Caribe. En M. del C. Feijoó y M. Poggi (Coord.), Educación y políticas sociales. Sinergias para la inclusión (pp. 49-76). Buenos Aires: Instituto Internacional de Planeamiento de la Educación IIPE-Unesco.

Dussel, I. (2004). Desigualdades sociales y desigualdades escolares en la Argentina de hoy. Algunas reflexiones y propuestas. Buenos Aires: FLACSO.

Echeverry, Y., y Jaramillo, J. (2006). El concepto de justicia en John Rawls. Revista Científica Guillermo de Ockham, 4(2), 27-52. Recuperado de http://www.redalyc.org/articulo.oa?id=105316853004

Fundación Universitaria Claretiana (FUCLA) (s. f.). El constructivismo social en la Fundación Universitaria Claretiana. El Modelo Pedagógico. Quibdó: Fundación Universitaria Claretiana (FUCLA).

Fundación Universitaria Claretiana (FUCLA) (2007-2008). Anuario FUCLA. Fundación Universitaria Claretiana, Número 1. Quibdó: Fundación Universitaria Claretiana (FUCLA).

Fundación Universitaria Claretiana (FUCLA) (2013a). Plan de Desarrollo 2014-2017 "Por la Paz y la Interculturalidad". Quibdó: Fundación Universitaria Claretiana (FUCLA).

Fundación Universitaria Claretiana (FUCLA) (2013b). Proyecto Educativo Universitario. Quibdó: Fundación Universitaria Claretiana (FUCLA).

Fundación Universitaria Claretiana (FUCLA) (2013c). Solicitud de renovación de registro calificado y modificación del programa de Trabajo Social. Quibdó: Fundación Universitaria Claretiana (FUCLA).

Gentili, P. (2009). Pedagogía de la igualdad. Ensayos contra la educación excluyente. Buenos Aires: Siglo XXI.

Herrera, M. C., y Infante, R. (2004). Las políticas públicas y su impacto en el sistema educativo colombiano. Una mirada desde los planes de desarrollo 1970-2002. Recuperado de https://ucentral.edu.co/images/editorial/nomadas/docs/nomadas_20_7_las_politicas.PDF

Imen, P. A. (2017). Política(s) y pedagogía(s) nuestroamericanas: un análisis en el contexto de los discursos del cambio y la innovación educativa. Recuperado de http://revistas.userena.cl/index.php/teduacion/article/ view/872 
Krichesky, M. (2016). "Desigualdad educativa en la región. Coordenadas de lectura para el contexto actual". Clase 2 del Seminario Desigualdades educativas en América Latina y el Caribe. Desafios actuales en prospectiva a una mayor justicia educativa. Buenos Aires: UNIPE-CLACSO.

Monedero, J. C. (2016). Reinventar la política. Reinventar la lucha por la igualdad. Madrid: CLACSO.

Nino, C. S. (1993). Justicia. Recuperado de http://www.academia. edu/31454905/Justicia

Puigross, A. (2017). La educación en América Latina. Legados, disputas y prospectivas [Clase Magistral. Curso Internacional - América Latina: Ciudadanía, Derechos e Igualdad]. Buenos Aires: CLACSO.

Rawls, J. (1971). Teoría de la Justicia. Cambridge: Harvard University Press.

Rivas, A. (2012). Dos caminos hacia la justicia educativa. Recuperado de https://www.youtube.com/watch?v=djUia--bJwk

Tedesco, J. C. (2008). La educación en el horizonte 2020. Educación y justicia: el sentido de la educación. Buenos Aires: Santillana.

Torres, R. M. (2005). Justicia educativa y justicia económica. 12 tesis para el cambio educativo. Quito: Fe y Alegría.

Universidad Nacional Abierta y a Distancia (2014). Seminario Internacional de Educación Inclusiva - Carlos Skliar Grande 540p. Recuperado de https://www.youtube.com/watch?v=G1vxLffM1ZY

Veleda, C., Rivas, A., y Mezzadra, F. (2011). La construcción de la justicia educativa. Criterios de redistribución y reconocimiento para la educación argentina. Buenos Aires: CIPPEC-UNICEF. 